\title{
Democratização, política externa e direitos humanos: uma releitura do caso brasileiro
}

\author{
Democratization, foreign policy and human \\ rights: a re-reading of the Brazilian case
}

\author{
DOI: $10.21530 /$ ci.v15n1.2020.983
}

Pablo de Rezende Saturnino Braga ${ }^{1}$

\section{Resumo}

A relação entre processos de democratização e a política externa é um tema bastante explorado nos campos da Ciência Política e Relações Internacionais, e o argumento deste artigo basicamente se apoia na revisão dessa literatura. No Brasil, a maior parte da literatura interpreta que a democratização teve impacto limitado nas linhas gerais da política externa brasileira. Todavia, na agenda de direitos humanos, o discurso da política externa foi reformulado para a recuperação das credenciais diplomáticas do Brasil. A democratização impulsiona a adesão dos países ao regime internacional de direitos humanos. A análise da adesão brasileira aos mecanismos de monitoramento internacional de direitos humanos demonstra, por outro lado, a lentidão dessa dinâmica, que seguiu o ritmo da natureza do processo de democratização, sem justiça de transição, e também a mudança das variáveis regionais e sistêmicas após o fim da Guerra Fria.

Palavras-chave: Processo de democratização; Política Externa Brasileira; Direitos Humanos.

\begin{abstract}
The relation between democratization processes and foreign policy is a widely explores theme in the fields of Political Science and International Relations, and the argument of this paper basically rests on the review of this literature. In Brazil, the literature interprets that democratization had limited impact on the general lines of Brazilian foreign policy. However, in the human rights agenda, the foreign policy discourse was reformulated for the recovery

1 Doutor em Ciência Política (IESP-UERJ) e mestre em Relações Internacionais (PUC-Rio), atua como professor da graduação em Relações Internacionais da Ibmec, analista de relações internacionais da FUNAG e é pesquisador do Labmundo (IESP-UERJ). ORCID: https://orcid.org/0000-0002-4553-2671; email: satbraga@gmail.com

Artigo submetido em 06/08/2019 e aprovado em 12/12/2019.
\end{abstract}


of Brazil's diplomatic credentials. The Democratization boosts the countries' adhesion to the international human rights regime. The analysis of the Brazilian adhesion to the international monitoring mechanisms of human rights shows, on the other hand, the slow pace of this dynamic, which followed the rhythm of the nature of the political transition, as well as the change of regional and systemic variables after the end of the Cold War.

Keywords: Democratization process; Brazilian Foreign Policy; Human Rights.

\section{Introdução}

No contexto do processo de democratização no Brasil, iniciado em 1985, dois movimentos concomitantes - globalização e democratização - incidem expressivamente sobre a política externa brasileira (PEB). Esse artigo analisa o impacto desses dois movimentos no projeto de inserção internacional do Brasil, com o objetivo de estudar a relevância dos direitos humanos no discurso e na ação da PEB no destacado contexto.

O artigo perpassa pelos governos de José Sarney (1985-1989), Fernando Collor (1990-1992), Itamar Franco (1992-1994), e Fernando Henrique Cardoso (1995-2002), a partir das dinâmicas identificadas da relação entre o processo de democratização e a política externa brasileira no campo dos direitos humanos e realiza uma reflexão final sobre a atual conjuntura de marcantes retrocessos no campo dos direitos humanos no governo Jair Bolsonaro (2019-). O debate sobre a democratização e suas consequências para a política externa já foi razoavelmente explorado pela literatura. Nos estudos sobre a PEB na transição democrática é dominante a análise sobre os efeitos relativamente inexpressivos da mudança de regime sobre a PEB (Pinheiro 2004; Cervo 2008; Lima 2000; Hirst e Pinheiro 1995; Oliveira 2005). Letícia Pinheiro afirma que "a redemocratização responde muito pouco por qualquer alteração no conteúdo da política externa” (Pinheiro 2004, p. 53). Sua posição é similar à de Amado Cervo (2008), para quem a transição do regime militar para o regime civil afetou apenas superficialmente a política exterior e o modelo de inserção internacional.

Essa continuidade da política externa se explica, em grande medida, pela preservação da autonomia do Itamaraty, que manteve distanciamento dos constrangimentos enfrentados pelo Estado brasileiro neste reordenamento político e econômico (Hirst e Pinheiro 1995). Para Oliveira (2005), as linhas gerais da PEB também são mantidas com o processo de democratização, e a defesa dos 
interesses do Terceiro Mundo permaneceu central para a diplomacia brasileira, em um contexto de crise da dívida externa e evidente vulnerabilidade dos países em desenvolvimento (Oliveira 2005)².

Mesmo antes do governo Sarney, a viagem oficial de Tancredo Neves como presidente eleito à América Latina, EUA e Europa teve como objetivo dar ao mundo o conhecimento do reencontro do Brasil com a democracia. O impacto positivo do périplo de Tancredo junto à opinião pública mundial e aos meios de comunicação criou um clima otimista sobre a inserção internacional do Brasil. "O consenso de Tancredo” (Casarões 2012; Belém Lopes 2017; Ricupero 2001; Ricupero 2005). O trecho abaixo explica as bases de sustentação do "consenso":

A solução é, mais uma vez, recorrer à sabedoria de Tancredo quando afirmava existir consenso nacional em torno não de política externa qualquer, mas daquela "conduzida pelo Itamaraty", como para acentuar a continuidade, a isenção, o profissionalismo e diferenciá-la de facções ou partidos, civis ou fardados (Ricupero 2005).

O “consenso" se definiu pela vinculação entre a democratização brasileira e sua política externa, bem como pela defesa dos valores democráticos na esfera internacional. Na prática, as mudanças se dariam muito mais no sentido de exaltação do novo momento brasileiro, mas constata-se a continuidade em termos de estratégias da política externa. Barreto (2012) assinala também a continuidade em linhas gerais, o que remete à tradição da política externa brasileira e permanência de seus princípios fundamentais. No entanto, aponta as mudanças em certos temas, em particular no que nos interessa, os direitos humanos.

A política externa no campo dos direitos humanos sinaliza importante mudança, ao menos no plano discursivo, dentro da estratégia de renovação das credenciais diplomáticas brasileiras. Ou, pelo menos, com a promessa de adesão aos acordos internacionais, sem questionar o campo político-conceitual dos direitos humanos tal como ele emana do Ocidente (com foco nos direitos civis e

2 Lima (2018) e Lima e Pinheiro (2018) produziram análises revisionistas sobre o conceito de "autonomia” na PEB. Grosso modo, ao contrário das leituras predominantes, as autoras identificam na autonomia os momentos excepcionais da PEB. Na verdade, o que se conveio em chamar de autonomia nos estudos da PEB, foi na prática uma diplomacia de prestígio que priorizou as arenas multilaterais para viabilizar um modelo de inserção econômica (o modelo de industrialização por substituição de importações) que, em grandes linhas, prevaleceu de 1940 até o fim da Guerra Fria. Este artigo se coaduna com tal revisão da literatura, porém ressaltamos que a revisão das autoras acima é muito mais abrangente no escopo da história da PEB do que o corte analítico deste artigo, mais focado na relação entre democratização e política externa. 
políticos). Segundo o Embaixador Seixas Corrêa, "a área dos direitos humanos, na realidade, foi talvez a que primeiro assinalou um curso novo para a diplomacia brasileira” (Seixas Corrêa apud Côrtes 2010, p. 236). As exigências mais protocolares para resgatar essas credenciais seriam garantidas, $a$ priori, com o processo de democratização e a participação do regime internacional de direitos humanos, com adesão aos acordos e tratados. Essa foi a forma que o Brasil acenou para uma inserção no regime internacional no início do processo de democratização, sem colocar em xeque o padrão de desigualdade social. O jurista Antônio Augusto Cançado Trindade destaca um novo processo histórico nas posições brasileiras na matéria dos direitos humanos iniciado no pós-1985 (Cançado Trindade 2006). Essa é uma linha defendida também por Côrtes, que discorre sobre o tópico:

É certa a dificuldade para se estabelecer correlação entre o regime político de um país e a formulação de sua política externa, mas a questão dos direitos humanos é inquestionavelmente uma área na qual esse vínculo pode ser apontado de forma concreta [...] a atitude assumida pelo Governo Sarney pretende, além de coadunar as liberdades políticas internas com sua conduta externa, estabelecer no cenário internacional a diferenciação entre a Nova república e o regime autoritário que a precedera (Côrtes 2010, p. 244).

Temas que antes figuravam em segundo plano na conjuntura militarista e ideológica da Guerra Fria e da ditadura militar brasileira, como meio ambiente e direitos humanos, tornam-se elementos relevantes da construção do discurso diplomático do Brasil. Almeida explica:

Era o início do resgate das hipotecas do Regime Militar. O Brasil adere aos regimes de direitos humanos e meio ambiente, temas bloqueados pelo "soberanismo" dos militares, nos quais o Brasil era alvo negativo da opinião pública internacional, por conta do desmatamento e das torturas aos presos políticos durante o regime anterior (Almeida, J.D.L. 2013, p. 568).

A bandeira dos direitos humanos, que ganhou vulto com a cruzada de Jimmy Carter, presidente dos EUA de 1977 a 1980, era tema tabu, principalmente pela questão da tortura perpetrada por oficiais brasileiros. A posição negacionista e abstenteísta deu a tônica da política externa de direitos humanos (PEDH) durante o regime militar, em que pese a conjuntura internacional dos anos 1970 de pressão de ONGs internacionais e a campanha de Carter (Roriz 2017). Os instrumentos internacionais sobre a matéria, como os pactos da ONU e a Convenção Americana 
sobre Direitos Humanos, foram elaborados durante a ditadura, regime marcado por profundas restrições aos direitos civis e políticos e liberdade de expressão (Côrtes 2010, p. 238). A dificuldade em lidar com temas de direitos humanos desgastou a imagem do Brasil no mundo, e o discurso da PEB passou a destacar essa agenda.

\section{O início do processo de democratização e a política externa no campo dos direitos humanos}

A partir de 1985, o Brasil subiu às tribunas dos principais foros mundiais enfatizando o respeito aos direitos humanos e à democracia. Em discurso na Assembleia Geral das Nações Unidas (AGNU), o presidente José Sarney anunciou a decisão de aderir aos dois pactos de direitos humanos da ONU, bem como à Convenção das Nações Unidas contra a Tortura:

Com orgulho e confiança, trago a esta Assembleia a decisão de aderir aos Pactos Internacionais das Nações Unidas sobre Direitos Civis e Políticos, à Convenção contra a Tortura e outros Tratamentos ou Penas Cruéis, Desumanos ou Degradantes, e sobre Direitos Econômicos, Sociais e Culturais. Com essas decisões, o povo brasileiro dá um passo na afirmação democrática do seu Estado e reitera, perante si mesmo e perante toda a Comunidade internacional, o compromisso solene com os princípios da Carta da ONU e com a promoção da dignidade humana (Seixas Corrêa 2012, p. 152).

O chanceler brasileiro, Otávio Setúbal, fez o mesmo no tocante à Convenção Americana sobre Direitos Humanos na Assembleia da OEA, em 1985 (Cançado Trindade 2006). Os três tratados foram ratificados apenas em 1992. O citado discurso de Sarney na Assembleia Geral da ONU apelou para a transição pacífica da democracia brasileira, e o seu assessor internacional, o embaixador Luiz Felipe Seixas Corrêa, reiterou que a democratização brasileira definiria a atuação externa do governo (Barreto 2012). A constitucionalização das práticas de política externa com os princípios que regem as relações internacionais do Brasil, estabelecidos na Constituição Federal de 1988, corrobora a relevância dos direitos humanos, consagrados em seu artigo $\mathrm{n}^{\circ} 4$, inciso II.

Paulo Sérgio Pinheiro (2001) discorre sobre essa abordagem dual da PEB, de continuidade quanto à sua inserção na comunidade internacional e de inovação criada pelo processo de democratização, e a área dos direitos humanos foi justamente a mais afetada pela nova orientação. Porém, em contraste com a 
retórica dos discursos e a assinatura dos tratados, a postura do governo frente às denúncias de ONGs internacionais foi defensiva e reativa, principalmente nos casos do extermínio de meninos de rua na Igreja da Candelária no Rio de Janeiro e a chacina de índios da comunidade Ianomâmi em Roraima, ambos em 1993 (Oliveira, M.D. 1999). Um exemplo foi a posição do Ministro da Justiça do governo, Paulo Brossard, que, em discurso transmitido nacionalmente, acusou a Anistia Internacional de ser uma organização subversiva por conta de relatório da ONG sobre violações de direitos humanos no Brasil (Pinheiro P. , 2001).

Apesar da mudança discursiva no início do processo de democratização, a agenda dos direitos humanos se inseriu mais como figura de retórica e não foi um tema com visibilidade do processo de democratização do Brasil. Cumpriu apenas um protocolo discursivo, o que explica em parte a demora na ratificação dos tratados supracitados. As elites política e diplomática inicialmente não acreditavam que para alavancar o processo de democratização os direitos humanos eram um aspecto central. Por isso o Brasil é um "late comer" na matéria, que ganhou real destaque na PEB a partir do governo Fernando Collor como veremos. Houve, portanto, um resquício da posição reticente em direitos humanos. Segundo Belli:

a plena aceitação da supervisão internacional sofreu ligeiro atraso em relação ao fim do regime militar e ao novo discurso em prol dos direitos humanos e da democracia. Houve uma fase transitória [...] em que a visão a respeito do papel do Brasil na $\mathrm{CDH}$ continha ainda resquícios da postura defensiva que prevalecera sob o regime militar” (Belli 2009, p. 172).

Em entrevista concedida ao autor, o embaixador Gilberto Saboia destacou que de fato havia uma resistência institucional à ideia de prestar contas aos mecanismos internacionais, e que a expectativa criada no início da democratização foi frustrada pelo entendimento de que as violações mais graves no Brasil não seriam resolvidas com o fim da ditadura, pois eram produto do sistema social e responsabilidade das elites (Saboia 2017).

$\mathrm{O}$ atraso na ratificação e aceitação dos instrumentos internacionais, ao nosso ver, se explica em parte pela natureza da transição política no Brasil, negociada entre as elites políticas militar e civil. A elite militar possuía muita influência no governo. O presidente José Sarney, por exemplo, foi presidente do partido governista, a Aliança Renovadora Nacional (ARENA). A eleição indireta de Tancredo Neves e Sarney como vice foi uma solução de compromisso entre 
situação e oposição, a qual ignorou as vozes das ruas no movimento "Diretas já”3. A “via lenta para a democratização brasileira” (Skidmore 1988) revela a natureza da transição política no Brasil, principalmente com a anistia dos agentes públicos responsáveis por violações de direitos humanos e a ausência de um processo de justiça de transição, que, portanto, demonstram a relativização da gravidade das violações de direitos humanos cometidas por agentes públicos durante o regime militar. Não havia um real comprometimento das elites com o tema dos direitos humanos, que não era prioridade - como explica a literatura sobre a relação entre a nova coalizão política e a antiga base de sustentação autoritária (Huntington 1991; Zallaquett 1992). Bernardi (2016) aponta fatores além da aliança de elites que consideramos relevantes, como a resistência da cúpula do judiciário em aceitar a interferência de cortes internacionais de direitos humanos e as dificuldades da sociedade civil se mobilizar para criar pressões no sentido da participação brasileira nos regimes de direitos humanos.

Apesar da não priorização da agenda dos direitos humanos, o discurso de Sarney na Assembleia Geral, quando assume o péssimo histórico do Brasil na temática dos direitos humanos, representa uma mudança em relação às políticas de negação que inspiravam a atuação diplomática do Brasil durante o regime militar e, inclusive, o discurso difundido nas diversas representações brasileiras pelo mundo. A mudança do discurso foi um passo inicial, ainda que insuficiente, para que os direitos humanos ganhassem destaque na nova narrativa da PEB. Esse movimento da política externa se deu em um contexto de reconquista das credenciais diplomáticas no início do processo de democratização. O anúncio da assinatura dos principais tratados enquadra-se, portanto, na interpretação de literatura que defende que o processo de democratização de um país o estimula a aumentar sua participação em acordos internacionais no campo dos direitos humanos (os mecanismos de Lock In) (Moravcsik 2000; Manfield e Pevehouse 2006; Hafner-Burton et al 20084). Concordamos com Bernardi (2016), que defende que os mecanismos Lock In não são suficientes para explicar a adesão do Brasil aos tratados e a mudança do discurso da PEDH. A lógica política doméstica e os valores que consubstanciam a inserção internacional do Brasil, consagrados na Constituição Federal, expressam uma vontade de mudança que não se esgota

3 O qual pressionou a aprovação da Emenda Constitucional Dante de Oliveira, de 1984.

4 Ver debate em Bernardi (2016). O autor discute outras razões que estimulam a adesão a tratados de direitos humanos e explora também a literatura que estuda os fatores que determinam a eficiência dos tratados para diminuir as violações de direitos humanos. 
apenas com o reconhecimento internacional. Na mesma linha, Belli ressalta que a gradativa adesão do Brasil aos mecanismos de monitoramento do regime representa a consolidação da escolha democrática da sociedade brasileira (Belli 2009). Ademais o impacto da mudança de regime político, a questão econômica é outro imperativo para a análise da PEB.

Na fase inicial do processo político de democratização, um fator que impacta a política externa é o esgotamento do modelo de industrialização por substituição e importações (ISI), evidenciado pela crise da dívida externa e a inflação galopante (Hirst e Pinheiro 1995). O modelo de política externa baseado no nacionaldesenvolvimentismo entrou em colapso nos anos 1980 (Bueno e Cervo 2008), com o crescimento descontrolado da dívida externa e da inflação, e a recessão econômica que atingiu o país em 1988. Mesmo iniciado o processo de democratização política, o quadro de instabilidade econômica que se estendeu até meados dos anos 1990 colocou a política externa em uma posição secundária na agenda dos tomadores de decisão por conta da centralidade da busca do equilíbrio macroeconômico. Maria Regina Soares de Lima explica que esse contexto distinguiu potencialmente o período militar do civil e diminuiu os espaços para inovações conceituais em matéria de política externa (Lima 1994); e esse é outro fator que contribui para o pequeno impacto da mudança de regime na política externa e também o uso da retórica dos direitos humanos, mas sem iniciativas expressivas no campo. Outro fator a ser considerado é apontado por Lima (1994) é o perfil do presidencialismo brasileiro, que por omissão ou delegação de poder, ou afinidade de pontos de vista, facilita maior autonomia do Itamaraty na elaboração da política externa.

Portanto, as variáveis explicadas, quais sejam, o modelo de desenvolvimento e a crise econômica, o perfil do processo de formulação da PEB e a natureza do processo de democratização explicam, em certa medida, as descontinuidades de estratégias de política externa que ocorrem em um mesmo regime, bem como continuidades em regimes distintos. Isso não significa que o processo de democratização não impulsione mudanças na PEB, mas demonstra apenas que essas variáveis diminuem o seu impacto de transformação, que é postergado.

\section{O fim da Guerra fria e a democratização: os direitos humanos em pauta}

Belém Lopes (2017) apresenta argumentos sobre a relação inextricável entre regime político e a PEB, e argumenta que as tradições da PEB se recombinam de 
modo distinto com os regimes políticos (BELÉM LOPES, 2017, p. 21). O processo de democratização, particularmente, produz efeitos importantes: a "poliarquização" da PEB, tendo em vista a diversificação de atores políticos e interesses em disputa na formulação da PEB; a constitucionalização de seus princípios em 1988; a "democratização" da PEB, haja vista as pressões para a maior transparência do processo de formulação e também maior participação no mesmo. Segundo o autor:

a PEB acompanhará, ainda que de forma idiossincrática e com uma cadência diferente, tanto discursiva quanto prática, a marcha rumo à democratização política — de resto, uma tendência global na década de 1980 (Belém Lopes 2017, p. 35).

A promulgação da Constituição Federal em 1988 e as primeiras eleições presidenciais diretas, em 1989, deram lastro ao processo de democratização, principalmente no sentido de neutralizar a ameaça do autoritarismo que ainda era muito presente no imaginário político. Na década de 1990, a nova ordem internacional pós-Guerra Fria criou também novos condicionantes políticos e econômicos. No governo Collor, aos aspectos domésticos soma-se a reorganização do sistema internacional pós-Guerra Fria, que definiu as tendências de globalização e regionalismo. O declínio do modelo ISI e a execução do receituário neoliberal impactaram diretamente a PEB. A inserção internacional brasileira foi definida pela liberalização comercial, estabilização macroeconômica, privatizações de serviços públicos e responsabilidade fiscal. O modelo neoliberal se tornou gradativamente um aspecto material do reconhecimento e elemento de socialização na comunidade internacional.

Do ponto de vista da dinâmica institucional-burocrática da formulação da política externa, a tese de que o Itamaraty havia sido insulado pelo perfil personalista de Collor na condução da PEB, foi refutada por Casarões (2012), que, por meio de entrevistas com atores-chave, demonstra que ocorreu no Itamaraty um amadurecimento da perspectiva de uma política externa a favor da liberalização comercial. Depois do alcunhado "consenso de Tancredo”, Paulo Tarso Flecha de Lima, secretário-geral do MRE no governo Sarney, já flertava com a liberalização comercial e aproximação com os EUA e alternativas ao globalismo como estratégia de ação a partir de uma lógica desenvolvimentista - que foi prevalecente no primeiro governo civil. O autor explica: 
A política externa do período [Collor] representou uma síntese entre o desejo de modernização, de abertura econômica e a busca pela autonomia de inserção internacional, fio condutor do Itamaraty e uma de suas mais importantes tradições [...] O período entre 1990 e 1992 foi reflexo direto de uma "tripla transformação" que acometeu o Estado brasileiro ao longo da década anterior, no tocante à produção de sua política exterior. Em primeiro lugar, caíram por terra as bases nacional-desenvolvimentistas que orientaram a inserção internacional do Brasil ao longo dos últimos governos militares. Segundo, o regime político sob o qual o País fora conduzido por mais de 20 anos, com fortes resquícios da Nova República adentro, também se reconfigurava, afirmando-se legitimamente democrático a partir da primeira eleição presidencial direta, em fins de 1989. Por fim, a mudança da ordem internacional - de uma estrutura bipolar aparentemente estável para uma não ordem com o ocaso da União Soviética e a implosão do Terceiro Mundo como bloco de poder - impôs a necessidade de reorientação internacional em especial aos países semiperiféricos, como parecia ser o caso do Brasil (Casarões 2012, p. 149).

Em suma, Collor não alijou o Itamaraty do processo de formulação da PEB, mas promoveu uma inflexão em consonância com perspectivas de dentro do MRE. As diretrizes de inserção internacional do Brasil foram construídas conjuntamente com os quadros do Itamaraty, definidos por Flecha de Lima como "liberais", enquanto outros quadros, com destaque para Paulo Nogueira Batista, eram classificados como "nacionalistas". Essas posições não eram novas na instituição diplomática, mas suas condições foram maturadas justamente pela incidência de novos fatores sistêmicos e domésticos. As disputas de visões de mundo na burocracia demonstraram a dificuldade do "consenso de Tancredo" ser viabilizado em um cenário de intensas transformações domésticas e internacionais. As mudanças sistêmicas foram também condicionantes importantes para o lugar de mais destaque que a temática dos direitos humanos assumiu no sistema internacional. A "vitória" do Ocidente fomentou a crença na superioridade da democracia liberal e realização dos seus ideais, como os direitos humanos a la Ocidente, traduzida pela tese do "Fim da História", de Francis Fukuyama (1992).

A agenda dos direitos humanos, dentro de uma ótica liberal-cosmopolita, gradativamente se firmou como elemento de legitimação do Brasil como um ator "responsável" no sistema. Os esforços para renovação das credenciais diplomáticas do Brasil, ainda inconclusos desde o governo Sarney, colocaram o tema da agenda neoliberal em sintonia com a participação do Brasil no regime internacional dos direitos humanos. O governo Collor abandonou a política de negação de 
violações de direitos humanos que prevaleceu no regime militar e ainda era presente com a abordagem defensiva no primeiro governo civil (Pinheiro 2001). O aumento da relevância da temática dos direitos humanos dentro na narrativa da “modernização ocidental” no cenário pós-Guerra Fria e a maior participação das ONGs brasileiras favoreceram uma nova percepção por parte das elites estratégicas sobre a vinculação entre a influência em instituições multilaterais e uma política externa mais transparente e atuante em questões de direitos humanos.

Em 1990, o chanceler Francisco Rezek recebeu uma missão da Human Rights Watch e, posteriormente, Collor foi o primeiro presidente brasileiro a receber representantes da Anistia Internacional. A importante presença das ONGs na Rio92 e na Conferência dos direitos humanos de Viena em 1993, apontavam para a maior relevância dos atores não-estatais no pós-Guerra Fria. O Itamaraty instruiu todas as missões brasileiras a contribuir e prover informações sobre direitos humanos e estar em contato permanente com as ONGs. A atuação coordenada de políticos (como Eduardo Suplicy, Severo Gomes e Fernando Henrique Cardoso) e diplomatas (Francisco Rezek e Celso Lafer) para acelerar a ratificação dos tratados, que ocorreu em 1992, refletiu essa mudança de mentalidade por parte das elites (Amorim 2017; Pinheiro, P. 2001).

O processo de democratização também é sujeito a oscilações e enfrentou, já em seu início, desafios importantes, principalmente a persistência da crise econômica e a instabilidade política criada pelo processo de impeachment de Collor em 1992. A crise política da jovem democracia brasileira, que deflagrou o impedimento do primeiro presidente eleito diretamente depois da ditadura militar, mais uma vez alimentou desconfianças sobre as possibilidades do país. Nos dois primeiros governos civis desde 1985 (Sarney e Collor), apesar dos avanços institucionais, com destaque para a Constituição de 1988, o reconhecimento da democracia liberal brasileira pela comunidade internacional ainda não havia sido consolidado. A natureza do processo de abertura, como já foi dito, sem participação popular e sem justiça de transição, gerou efeitos negativos para a imagem brasileira. $\mathrm{O}$ insucesso dos planos econômicos ${ }^{5}$ em estabilizar a moeda e os preços desde a democratização adicionaram mais ingredientes à instabilidade. Com o impedimento de Collor, as desconfianças em relação ao Brasil cresceram, como explicam Hirst e Pinheiro:

5 No governo Sarney, os planos Cruzado II em 1986, Bresser em 1987 e Verão em 1989; e o plano Collor em 1990. 
Apesar do esforço do Itamaraty de manter o curso da política externa de forma independente da crise política nacional, foi impossível evitar a deterioração da imagem do Brasil na comunidade internacional, particularmente junto às Nações industrializadas (Hirst e pinheiro 1995, p. 7).

No governo interregno de Itamar Franco (1992-1994), o campo dos direitos humanos foi um dos principais destaques na agenda de política externa. A preparação para II Conferência Internacional de Viena em 1993, cujo comitê de redação foi presidido pelo embaixador brasileiro, Gilberto V. Saboia, contribuiu para consolidar a política externa brasileira de direitos humanos (Pinheiro, P. , 2001). A redação colocou termo à questão sobre a indivisibilidade dos direitos humanos, consagrada no texto, abordagem que refuta a teoria das "gerações de direitos". Os trabalhos preparatórios para a Conferência de Viena estimularam um diálogo a nível nacional entre Estado e sociedade civil em torno da matéria (Cançado Trindade 2006). Tratou-se de um marco por ter sido o primeiro encontro na história da diplomacia brasileira que promoveu o diálogo entre Estado e sociedade civil em temas de direitos humanos, com o seminário "Democracia, Desenvolvimento e Direitos Humanos” (Oliveira, M.D. 1999; Pinheiro, P. , 2001). Passado o estágio da ratificação, situava-se no horizonte da PEDH a aceitação dos mecanismos de fiscalização de comitês e cortes de direitos humanos, que seria o estágio final para alinhavar o Brasil aos regimes regional e internacional de direitos humanos (Saboia 2017).

\section{A consolidação das credenciais diplomáticas e os direitos humanos}

Nos governos de Fernando Henrique Cardoso (FHC) (1995-2002), a combinação entre a liberalização política e abertura econômica resultou no surgimento de uma nova fase da PEB, à procura de uma "integração competitiva” (Lima 2000, p. 295). A estratégia pressupôs que as limitações de poder do Brasil poderiam ser mitigadas ou diminuídas em um sistema internacional que segue e respeita as regras internacionais. Dessa forma, a regulamentação dos regimes internacionais e o respeito às normas foram os meios para viabilizar a autonomia do Brasil. A adesão aos regimes internacionais foi a evidência mais expressiva dessa estratégia. 
A política externa de FHC orientou-se pelo tripé “democracia, estabilidade monetária e abertura econômica”, como o próprio definiu em artigo publicado na Revista Brasileira de Política Internacional (Cardoso 2001). Segundo Sylvia Marques:

No governo Cardoso, o país é visto como confiável não apenas em razão de seu respeito às normas internacionais, sua índole pacifista e não expansionista, e seu histórico de resolução de conflitos pela diplomacia. Mas também por ter alcançado a estabilidade econômica pelas reformas neoliberais e consolidada a democracia com economia liberal de mercado" (Marques 2005, p. 80).

A concepção de uma “soberania compartilhada” permitiu a percepção de um mundo com valores universais resguardados por regimes com mais espaços de atuação para potencias médias, como o Brasil. E o Brasil buscou construir essa imagem, como potência média respeitadora das normas internacionais (MARQUES, 2005, p. 81).

A PEB do governo FHC partiu do diagnóstico de que o Brasil estava relativamente longe de possuir ativos que lhe confeririam condições para reclamar a posição de uma grande potência (Rocha 2006). Com o esforço de integração do Brasil aos mecanismos dos regimes internacionais, a questão dos direitos humanos apresentou-se como um tema relevante, parte do discurso legitimador da ordem liberal. As incongruências da construção desse discurso e também de suas práticas não estavam na ordem do dia no projeto brasileiro desenvolvido no governo FHC. Esse projeto teve como um dos seus objetivos centrais equacionar os dividendos para, enfim, consolidar as credenciais diplomáticas brasileiras. Alguns eventos são marcantes para a participação do Brasil nos regimes internacional e regional dos direitos humanos.

Domesticamente, a elaboração, em 1996, do I Plano Nacional de Direitos Humanos (o primeiro do tipo em toda a América Latina e terceiro no mundo, depois de Austrália e Filipinas), conforme recomendações da Conferência de Viena em 1993 (Pinheiro, P. 2001), marca a aproximação entre a política externa e os instrumentos jurídicos para a defesa dos direitos humanos. As mudanças institucionais domésticas foram concatenadas com medidas importantes no cenário internacional. A aceitação da competência obrigatória em matérias contenciosas da Corte Interamericana de Direitos Humanos (Corte IDH), conforme artigo 62 da Convenção Americana sobre Direitos Humanos, em dezembro de 1998, é um marco 
para a política externa brasileira no campo ${ }^{6}$.Depois de aceitar a competência da Corte IDH, o Brasil passa a aceitar instrumentos internacionais com poder de interferir em matérias de direitos humanos domesticamente (Belli 2009): em 2000, assinou o Estatuto de Roma, que criou o Tribunal Penal Internacional (TPI), ratificando-o em 2002; assinou, em 2001, o convite permanente (standing invitation) para a visita de relatores especiais e peritos independentes dos Procedimentos Especiais da ONU; e, em 2002, se tornou parte do Protocolo Opcional da Convenção para a Eliminação de Todas as Formas de Discriminação contra a Mulher, reconhecendo a competência do respectivo comitê de monitoramento para receber denúncias individuais (Ballestrin 2008).

A aceitação da competência de uma corte internacional e a permissão de denúncias individuais sacramentam a superação da fase negacionista do Brasil em relação aos regimes internacional e regional de direitos humanos e um passo além da retórica discursiva no campo quando iniciado o processo de democratização ${ }^{\text {. }}$. A maior abertura do Brasil aos mecanismos internacionais de fiscalização de violações de direitos humanos colocou o País em outro patamar internacional, com maior transparência em relação aos problemas de direitos humanos que ocorrem em território brasileiro. O reconhecimento das dificuldades do país no campo reposicionou a imagem internacional do Brasil (Rocha 2006).

Essa foi a dimensão estratégica da PEDH no governo FHC: simultaneamente, contribuiu para legitimar o processo de democratização, e potencializar o poder de barganha nas negociações internacionais, por reforçar a imagem do país como um ator que aceita e respeita as normas, assume os problemas que possui no campo de forma transparente e se propõe a enfrentá-los. O governo FHC foi bem-sucedido no objetivo de consolidar a renovação das credenciais diplomáticas brasileiras no sistema internacional e superar as desconfianças em relação à estabilidade política e econômica do País. E a PEDH foi insumo imprescindível para esse êxito. Essa consolidação pode ser observada a partir de análises nos níveis sistêmico, regional e doméstico.

No nível sistêmico, o conjunto de acontecimentos (a queda do Muro de Berlim e o colapso soviético) que levam a uma nova ordem internacional é cronologicamente posterior ao início do processo de democratização do Brasil,

6 O decreto presidencial ocorreu apenas no final do governo FHC, em 8 de novembro de 2002.

7 Ademais esses marcos, no governo FHC o Brasil aderiu: aos dois Protocolos adicionais da Convenção Americana sobre Direitos Humanos, em agosto de 1996; ao Protocolo de San Salvador, de 1988, sobre Direitos Econômicos, Sociais e Culturais; e ao Protocolo referente à Abolição da Pena de Morte, de 1990. 
e os condicionamentos sistêmicos são colocados principalmente pela perspectiva da vitória dos ideais liberais e proliferação dos debates multilaterais sobre temais globais. A PEB reivindica uma legitimidade que deriva de sua fidelidade ao sistema multilateral e essa é uma pedra angular da tradição diplomática brasileira (Fonseca Jr. 2014). Justamente nela estão escorados princípios construídos em nossa história e consagrados na Constituição Federal: o pacifismo, que representa a crença na resolução negociada das controvérsias sem apelar aos recursos militares; a não-intervenção, a qual só pode ser legitimada dentro do escopo previsto na Carta da ONU; a autonomia, que expressa a capacidade do país agir sem coações políticas e econômicas.

Essas características certamente são reforçadas pela ênfase no multilateralismo, depois de uma política externa que se distanciou da via multilateral nos “anos de chumbo" (Fonseca Jr. 1999). Novos caminhos para a atuação multilateral são abertos pela diversificação de temas globais nas conferências da ONU na década de 1990, e o Brasil reforça sua atuação multilateral, principalmente nos campos em que sua atuação era defensiva, como nos temas de direitos humanos e meio ambiente. Belém Lopes observa que um dos méritos de FHC foi reconhecer “o nexo entre a democratização das sociedades nacionais e a democratização das relações internacionais” (Belém Lopes 2017).

No plano regional, o paralelismo histórico com a democratização da América do Sul permite a superação da hipótese de guerra com a Argentina, que sempre esteve presente no processo de formulação da política externa no século XX. O processo de democratização nos dois países foi a principal variável explicativa dos acordos energético e nuclear, que são as sementes da integração regional que vieram a germinar e viabilizar o Mercosul. Isso mudou as possibilidades de relação do Brasil com seus vizinhos e com o mundo. O conteúdo moral da narrativa brasileira se fortalece com a perspectiva da integração regional e abdicação do armamento nuclear. A opção brasileira de abdicar da bomba atômica criou um espaço de contestação ao poder e projetou de forma mais consistente a imagem de uma "potência da paz" profetizada por Afonso Arinos.

No nível doméstico, o processo de democratização ganha mais solidez, simbolizada pela promulgação da nova carta magna e as primeiras eleições diretas, mesmo em conturbado contexto econômico e político. A estabilidade macroeconômica, com o plano Real e a eleição de FHC, garantem o reconhecimento internacional do processo de democratização do País. 
Em suma, a narrativa da PEB com o processo de democratização se desprende das principais amarras que afligiam a coerência dessa trajetória, principalmente o sistema de poder bipolar da Guerra Fria, o regime militar e a contestação crescente à sua legitimidade, e as tensões militares na região no período. Não se trata, entretanto, de um novo paradigma de política externa que surge com a democratização e fim da Guerra Fria. Existe, em nossa perspectiva, uma dependência da trajetória, que ressignifica as tradições da política externa.

Os padrões de legitimidade que constroem a narrativa da PEB nesse processo de democratização têm transversalidade com a atuação brasileira no campo dos direitos humanos. Nesse ponto, a transparência e a maior participação da sociedade civil propiciam uma resposta razoável quanto à situação paradoxal de um país cujo discurso diplomático enfatiza o respeito aos direitos humanos, porém domesticamente apresenta quadros de violações graves. Esse nexo doméstico-internacional cria pressões democratizantes sobre o processo de formulação da PEB.

\section{Conclusões}

Como visto, no momento inicial do processo de democratização, a agenda dos direitos humanos passou a ser parte do discurso diplomático brasileiro, porém sem inovações conceituais que de fato colocassem a agenda como elemento importante na formulação da PEB. Gradativamente, a política externa no campo ganhou espaço além do plano retórico e legalístico. Como destacou Corrêa: "A política externa da Nova República na área dos direitos humanos representa, assim, mais do que uma mera inflexão na linha de atuação da diplomacia brasileira, uma verdadeira inovação" (Corrêa 2010, p. 245). A PEB acompanhou o rumo da democratização política, embora com cadência diferente, e certo atraso do Itamaraty em entender as transformações impostas pelo processo de democratização (Belém Lopes 2017). A natureza da democratização no Brasil, negociada com os grupos no poder, remete à abertura "lenta, gradual e segura" iniciada ainda nos anos 1970 pelo governo do general Geisel, bem como à anistia "ampla, geral e irrestrita” de 1979. A natureza da transição contribuiu para que o impacto da democratização no processo de formulação da política externa não fosse sentido abruptamente (em intensidade e velocidade).

O efeito foi especialmente sentido na política externa no campo dos direitos humanos. Roriz (2017) explica o foco da democracia como vanguarda das demandas 
na abertura e não o campo dos direitos humanos, principalmente depois da anistia. Ainda assim não se pode desprezar a relevância da inclusão da temática dos direitos humanos no discurso do primeiro governo pós-ditadura militar, mesmo que não tenha significado uma política externa com ênfase nessas questões. Isso pavimentou o caminho para mudanças subsequentes nas estruturas burocráticas e eventualmente em ações de política externa. Belli afirma:

Não resta dúvida de que o fim do ciclo autoritário e a inauguração de um governo civil em 1985 constituíram ponto de inflexão, marcando o fim de um período eminentemente defensivo, em que a presença nos foros de direitos humanos tinha o objetivo de impedir eventuais condenações morais do país, para um período de adesão crescente às obrigações derivadas dos instrumentos internacionais (Belli 2009, p. 170).

O Brasil não apenas se dispôs a solucionar prontamente as graves lacunas de não adesão aos três tratados gerais de proteção (dois tratados de direitos humanos da ONU e a Convenção Americana), mas também pela participação propositiva nos foros de debate sobre a questão dos direitos humanos, em especial a Conferência de Viena, em 1993.

O fio condutor para que as questões de direitos humanos fossem incorporadas pela PEB foi a percepção crescente por parte das elites política e diplomática de que a integração do Brasil à economia global e reconhecimento de sua transição democrática eram inseparáveis da promoção dos direitos humanos na esfera internacional (Pinheiro, P. 2001). A influência das ONGs como atores políticos no cenário político brasileiro contribuiu para que a bandeira dos direitos humanos gradativamente ganhasse espaço na narrativa da PEB com o avanço do processo de democratização (Oliveira, M.D. 1999). Essas variáveis domésticas e internacionais deslocaram a agenda dos direitos humanos para um eixo estratégico da inserção internacional brasileira, principalmente porque a ideia foi disseminada entre lideranças das elites política e diplomática nos anos 1990, quando alguns importantes operadores da política externa criaram iniciativas no campo (Pinheiro, P. 2001).

A estratégia de legitimação da democracia brasileira passou, no governo FHC, por esse movimento de adesão aos principais instrumentos internacionais, culminando na aceitação da obrigatoriedade de cortes internacionais, como o TPI e a Corte IDH. A mudança, que se deu inicialmente no plano retórico, passou para um momento de ratificações no início da década de 1990, e, a partir da aceitação da competência judicial da Corte IDH entra em uma nova fase de "relativização 
da soberania”, com a decisão do convite permanente para peritos internacionais e a abertura para petições individuais a vários organismos de tratados de direitos humanos. A "adesão" superou o ceticismo que era estimulado não apenas pela memória do perfil reticente da política externa no campo dos direitos humanos durante o regime militar, como também pela natureza do processo de transição com a eleição indireta, o impedimento do primeiro presidente eleito diretamente e a persistente instabilidade macroeconômica. Fatores domésticos e internacionais influenciam essa mudança progressiva de uma PEDH que enfatizou retoricamente os princípios dos direitos humanos para uma PEDH comprometida substancialmente com os tratados e aberta aos mecanismos de monitoramento de violações dos regimes internacional e regional de direitos humanos.

O governo FHC superou a percepção duvidosa da comunidade internacional sobre o regime democrático brasileiro e o lugar da PEDH foi estratégico dentro da concepção de "desenvolvimento associado" ao neoliberalismo. A eleição de Luís Inácio Lula da Silva (2003-2011) iniciou um novo momento para a PEB, marcada pelo sentimento de mudança expresso nas urnas em 2002, e reorientou a atuação do Brasil no campo dos direitos humanos, com um foco em direitos sociais e uma posição crítica quanto à politização dos direitos humanos no âmbito do regime internacional - a qual ensejou uma diplomacia reformista de instituições internacionais (Bueno e Cervo 2008; Cepaluni e Vigevani 2007). Ainda que sem uma diplomacia presidencial forte, o governo Dilma Roussef (2011-2016) manteve as linhas de força dessa atuação revisionista da PEDH.

Após o impeachment controverso que destituiu a presidente Dilma Roussef em 2016, o governo Temer apresentou seu plano de política externa. O discurso do chanceler, José Serra, no dia 18 de maio de 2016 (MRE 2016), deu ênfase a aspectos comerciais, e não especificou o perfil de atuação do Brasil no campo dos direitos humanos. O $\mathrm{CBPEDH}^{8}$ manifestou sua preocupação em carta pública (CBPEDH 2016). O congelamento de gastos sociais após a aprovação da Emenda Constitucional 95 (Senado Federal, 2016), foi criticada por organismos internacionais, como a CEPAL (ONU 2017). O relator especial da ONU para extrema pobreza e direitos humanos, Philp Alson, afirmou que a emenda viola os direitos humanos no Brasil e coloca o país em uma "categoria única em matéria

8 O Comitê Brasileiro de Direitos Humanos e Política Externa foi criado é um grupo permanente de acompanhamento da política externa brasileira que surgiu durante a audiência pública "Política Externa e Direitos Humanos", realizada em 28 de Setembro de 2005, na Câmara dos Deputados, por iniciativa da CDHM - Comissão de Direitos Humanos e Minorias. 
de retrocesso social" (ACNUDH 2017). Por conta das políticas de austeridade, o Brasil votou contra uma resolução do Conselho de Direitos Humanos da ONU em abril de 2017 que renovou o mandato da organização de monitorar os impactos das políticas fiscais de cada país sobre os direitos humanos de seus cidadãos. Nos anos 2008, 2011 e 2014, o país votou favoravelmente, conforme tradição brasileira de aderir às resoluções temáticas do $\mathrm{CDH}$. Ainda que o governo Temer (2016-2018) tenha revertido essas tendências na temática de direitos humanos, não representou uma mudança do discurso do Brasil pós-democratização, no sentido de questionamento conceitual dos direitos humanos, tal como ocorre no atual governo de Jair Bolsonaro (2019-).

O novo Ministério da Mulher, da Família e dos Direitos Humanos (que incorporou as secretarias de gênero e de questões raciais) expressa uma visão superficial e deturpada dos direitos humanos, pautada, inclusive, por um modelo heteronormativo ${ }^{9}$ de família e conservadorismo religioso ${ }^{10}$. No campo da PEDH, o Brasil adota uma postura de reversão do posicionamento construído na esteira do processo de democratização. A conjunção da visão dos direitos humanos e a diplomacia ficou latente com a decisão do governo suprimir o conceito de "gênero" e incluir a "promoção da família" no texto de sua candidatura ao CDH em 2019. Na mesma ocasião, nos votos da $41^{\text {a }}$ sessão do $\mathrm{CDH}$, o Brasil atuou para enfraquecer as resoluções temáticas, criando as chamadas "emendas hostis". Em votação sobre o tema da educação sexual (CDH 2019a), por exemplo, apoiou a mudança proposta pelo Paquistão, de excluir a recomendação de "garantir o acesso universal à educação abrangente sobre sexualidade baseada em evidências”. Em resolução contra o casamento infantil e forçado, o Brasil votou a favor de uma emenda proposta por Egito e Iraque para excluir do texto uma referência "ao direito à saúde sexual e reprodutiva" (CDH 2019b). Essa posição diverge da atuação diplomática brasileira desde a reforma que criou o CDH em 2006. Em resoluções temáticas, o Brasil atuava no sentido de ampliar os temas de discussão, como fez ao introduzir, em 2011, a questão de identidade de gênero e orientação sexual nas discussões do Conselho (CDH 2011). A PEDH é um vetor da diplomacia da ruptura de Bolsonaro (Spektor 2019).

9 Refere-se à heteronormatividade, conceito de que apenas os relacionamentos entre pessoas de sexos opostos ou heterossexuais são normais ou corretos.

10 Alguns episódios envolvendo a ministra dos direitos humanos, Damares Alves, ilustram esse viés, como a fatídica frase de que no governo Bolsonaro, “meninas vestem rosa, e meninos vestem azul” (O GLOBO, 2019). 
Essa ruptura com a narrativa de política externa produzida desde a democratização até o impedimento de Dilma Roussef é o resultado, ademais outros fatores, da fragilidade do processo de democratização brasileiro e da ausência de uma justiça de transição, que revelam e confirmam a precariedade da afirmação jurídica e empírica dos direitos humanos no país. Esses acontecimentos reforçam a importância da abertura de novas agendas de pesquisa que estudem as recentes transformações na área de política externa brasileira e direitos humanos.

\section{Referências}

ACNUDH. Brazil 20-year public expenditure cap will breach human rights, UN expert warns. 2017. Disponível em: < http://www.ohchr.org/EN/NewsEvents/Pages/ DisplayNews.aspx?NewsID = 21006 > . Acesso em: 02. ago. 2019.

Almeida, João Daniel Lima de. História do Brasil. Brasília: FUNAG, 2013, 595 p.

Amorim, Celso. Entrevista concedida ao autor. Rio de Janeiro, 30 de março de 2017. 1 arquivo mp3.

Ballestrin, Luciana Maria de Aragão. Direitos Humanos, Estado e Sociedade Civil nos governos de Fernando Henrique Cardoso (1994-2002). Teoria \& Sociedade (UFMG), v. 16.2, p. 10-33, 2008.

Barreto Fernando de Melo. A Política Externa após a Redemocratização. Tomos 1 e 2. Brasília: FUNAG, 2012.

Belém Lopes, Dawisson Belém. Política externa na Nova República: os primeiros 30 anos [Prefácio de Sean Burges]. 1. ed. Belo Horizonte: Editora UFMG, 2017.

Belli, Benoni. A Politização dos Direitos Humanos. São Paulo: Perspectiva, 2009.

Bernanrdi, Bruno Boti. Justiça de transição e as leis de anistia na Corte Interamericana de Direitos Humanos. In: Impacto das Decisões da Corte Interamericana de Direitos Humanos na Jurisprudência do STF, Editora JusPodivm, 2016, pp. 411-444.

Bueno, Clodoaldo e Cervo, Luiz Amado e História da Política Exterior do Brasil. Brasília: Editora da UnB, 2008.

Cançado Trindade, A.A. A Humanização do Direito Internacional, Belo Horizonte, Edit. Del Rey, 2006, pp. 3-423, 2006.

Cardoso, Fernando Henrique. A política externa do Brasil no início de um novo século: uma mensagem do Presidente da República. In: Revista Brasileira de Política Internacional, 44 (1), 2001, pp. 5-12.

Casarões, Guilherme Stolle Paixão e. "O papel do Itamaraty na definição da política externa do governo Collor de Mello. In. Revista Brasileira de Política Internacional. No 55, vol. 1, pp. 135-153, 2012. 
CDH. Resolução A/HRC/41/L.26. 2019a. Disponível em: < https://documents-dds-ny. un.org/doc/UNDOC/LTD/G19/208/94/PDF/G1920894.pdf?OpenElement > . Acesso em: 17 jul. 2019.

CDH. Resolução A/HRC/41/L.8/Rev.1. 2019b. Disponível em: < https://documents-ddsny.un.org/doc/UNDOC/LTD/G19/211/10/PDF/G1921110.pdf?OpenElement > . Acesso em: 17 jul. 2019.

CDH, Resolução A/HRC/RES/17/19. 2011. < http://ap. ohchr.org/documents/dpage_e. aspx?si = A/HRC/RES/17/19 > . Acesso em: 17 jul. 2019.

COMITÊ BRASILEIRO DE POLÍTICA EXTERNA E DIREITOS HUMANOS (CBPEDH). Carta Pública: Retrocesso dos DH e da participação social na nova condução da PEB. 2016. Disponível em: < http://dhpoliticaexterna.org.br/?p=567 > . Acesso em: 02. ago. 2019.

Cepaluni, Gabriel e Vigevani, Tulio. “A política externa de Lula da Silva: a estratégia da autonomia pela diversificação”. Revista Contexto Internacional, Vol. 29, n. 2, 2007, pp. 273-335.

Cervo, Amado Luiz. Conceitos em Relações Internacionais. Rev. bras. polít. int., Brasília, v. 51, n. 2, p. 8-25, Dec. 2008.

Côrtes, Octávio H. A Política Externa do Governo Sarney. Brasília: FUNAG, 2010, 372 P.

Fonseca Jr., G. A legitimidade e outras questões internacionais. 2. ed. São Paulo: Paz e Terra, 1999.

Fonseca Jr., G. Apontamentos para o estudo da diplomacia multilateral do Brasil: momentos fundadores e temas políticos nas nações unidas. UFRGS, Tese de Doutorado, 2014, 207 p.

Fukuyama, Francis. The end of history and the last man. New York: The Free Press, 1992

Hafner-Burton, Emilie, Mandfield, Edward D. e Pevehouse, Jon C. Democratization and human rights regimes. Trabalho apresentado na reunião da International Studies Association (ISA), 2008ew.

Hirst, Mónica e Pinheiro, Letícia. A política externa do Brasil em dois tempos. Rev. Bras. Polít. Int. 38 (1): 5-23 [1995].

Huntigton, Samuel. Democracy's Third Wave. The Journal of Democracy, 2(2), 1991.

Lima, Maria Regina Sores de. Política externa brasileira em debate: dimensões e estratégias de inserção internacional no pós-crise de 2008/organizadores: Walter Antonio Desiderá Neto... [et al.]; Brasília: Ipea — Funag, 2018, 626 p.

Lima, Maria Regina Sores de. A política externa brasileira e os desafios da cooperação Sul-Sul. Rev. Bras. Polít. Int., 2005, n. 48 (1), pp. 24-59.

Lima, Maria Regina Sores de. Instituições democráticas e política exterior Contexto Internacional, Rio de Janeiro, v. 22, n. 2, p. 265-303, 2000.

Lima, Maria Regina Sores de. Ejes analíticos y conflicto de paradigmas en la política exterior brasileña. In: América Latina/Internacional, vol. 1, n. 2, 1994, pp. 27-46. 
Lima, Maria Regina Soares de e Pinheiro, Letícia. Between Autonomy and Dependency: the Place of Agency in Brazilian Foreign Policy. Brazilian Political Sci. Rev., São Paulo, v. 12, n. 3, 2018.

Manfield; Edward D. e Pevehouse, Jon Pevehouse. Democratization and international organizations. International Organization 60 (1): 137-67, 2006.

Marques, Sylvia Ferreira. A imagem internacional do Brasil no Governo Cardoso (19952002): uma leitura construtivista do conceito de potência media. Rio de Janeiro, 2005. Dissertação (Mestrado em Relações Internacionais - Instituto de Relações Internacionais). PUC-Rio.

MRE, 2016, Discurso do ministro José Serra. < http://www.itamaraty.gov.br/pt-BR/ discursos-artigos-e-entrevistas-categoria/ministro-das-relacoes-exteriores-discursos / 14038-discurso-do-ministro-jose-serra-por-ocasiao-da-cerimonia-de-transmissao-docargo-de-ministro-de-estado-das-relacoes-exteriores-brasilia-18-de-maio-de-2016 > . Acesso em: 06 ago. 2019.

MRE, 2019. Discurso da ministra Damares Alves. < http://www.itamaraty.gov.br/pt-BR/ discursos-artigos-e-entrevistas-categoria/outras-autoridades-discursos/20089discurso-da-ministra-da-mulher-da-familia-e-dos-direitos-humanos-damares-alves-naabertura-do-segmento-de-alto-nivel-da-40-sessao-do-conselho-de-direitos-humanosdas-nacoes-unidas > . Acesso em: 09 jul. 2019.

Moravcsik, Andrew. The origins of human rights regimes: democratic delegation in postwar Europe. International Organization, v. 54, n. 2, p. 217-252, 2000.

Oliveira, Herique Altemani. Política externa brasileira. São Paulo: Saraiva, 2005.

Oliveira, Miguel Darcy de. Cidadania e globalização: a política externa brasileira e as ONGs. Brasília: FUNAG. 1999, 143 p.

ONU. CEPAL vê com preocupação congelamento do gasto público brasileiro. 2017. Disponível em: < https://nacoesunidas.org/cepal-ve-com-preocupacao-congelamentodo-gasto-publico-brasileiro/ > . Acesso em: 02. ago. 2019.

O Globo Ver: < https://oglobo.globo.com/sociedade/menino-veste-azul-menina-vesterosa-diz-damares-alves-em-video-23343024 > . Acesso em: 06 ago. 2019.

Pinheiro, Leticia. 2004. Política Externa Brasileira. Rio de Janeiro, Jorge Zahar Ed., 2004, 81 p.

Pinheiro, Paulo Sérgio. Brazil and the International Human Rights System. Center for Brazilian Studies - Working Paper Series, CBS-15-00, Oxford, v. CBS, n. 15, 2001.

Ricupero, R. O que restou do consenso de Tancredo? Folha de S. Paulo, 30 jan. 2001. < http://www1.folha.uol.com.br/fsp/dinheiro/fi3012200106.htm > . Acesso em: 06 set. 2018.

Ricupero, R. O fim do Consenso? Folha de S. Paulo, 12 jun. 2005. < http://www1.folha. uol.com.br/fsp/dinheiro/fi1206200504.htm > . Acesso em: 06 set. 2018. 
Rocha, A.J.R. O Brasil e os regimes internacionais. In: Henrique Altemani de Oliveira e Antonio Carlos Lessa. (Org.). Relações internacionais do Brasil - Temas e agendas. 1ed. São Paulo: Saraiva, 2006, v. 2, p. 75-124.

Roriz, João Henrique. Clashing frames: human rights and foreign policy in the Brazilian re-democratization process. Rev. bras. polít. int., Brasília, v. 60, n. 1, 2017.

Saboia, Gilberto de Vergne. Entrevista concedida ao autor. Rio de Janeiro, 23 de junho de 2017. 1 arquivo mp3.

Seixas Côrrea, Luiz Felipe de. O Brasil nas Nações Unidas. 1946-2011. Organizador. FUNAG: Brasília, 2012, 988 p.

Senado Federal. Emenda Constitucional 95. 2016. < https://www2.camara.leg.br/legin/ fed/emecon/2016/emendaconstitucional-95-15-dezembro-2016-784029-publica caooriginal-151558-pl.html > . Acesso em: 06 ago. 2019.

Skidmore, Thomas E. A lenta via brasileira para a democratização: 1974-1985. In: Democratizando o Brasil. Alfred Stepan (Org.). Rio de Janeiro: Paz e Terra, 1988, p. 27-81.

Spektor, Matias. Diplomacia da ruptura. In: Democracia em risco? 22 ensaios sobre o Brasil hoje. São Paulo: Editora Companhia das Letras, 2019, 376 p.

Zallaquett, José. Balancing Ethical Imperatives and Political Constraints: the dilema of new democracies confronting past Human Rights violations. Hasting Law Journal 42(6), pp. 1425-38, 1992. 